\title{
Observing young children's play: a brief review
}

\author{
KURT, GöKCE \\ Eötvös Loránd University, Faculty of Primary and Pre-School Education
}

\begin{abstract}
The observational techniques are significant tools to inform educational practice and research. Thanks to their advantage of providing authentic data, these techniques are vastly used to inform theory and practice in the field of early childhood education and development. In this brief review; (1) the observational methods, (2) the observational settings, (3) the types of observations, (4) the observational tools, and (5) the ethical considerations have been delineated in the context of educational research and practice.
\end{abstract}

Keywords: play, young children, observation, play assessment, observational studies

\section{Observational methods in early childhood education and development}

In the field of early childhood education and development, the observational studies have been always popular because of their way of direct data collection from diverse settings such as homes, schools, and outdoor settings. Cohen, Manion, and Morrison (2002) described the data collected from observations as "live" data as this kind of data comes directly from the natural settings. Generally, the observational studies sought in the area of early childhood education and development aim to answer some specific research questions and they have some limitations within the scope of the study undergone. However, most of the developmental research and theories have their data collected through the observational techniques (Mukherji E Albon, 2015).

The observational studies refer to the research in which the observational techniques are used during the whole study (Mukherji $\mathcal{E}$ Albon, 2015). Besides, there are some studies in which the observational techniques are employed as a part of the study. Generally, the qualitative methodologies (e.g., case studies, ethnographies) employ prolonged hours of observations in the natural settings (Creswell, 2013). Even the experimental designs may involve observations although they are taken out in the structured settings with possible interventions (Punch \& Oancea, 2014). The observational studies do not only provide a deeper understanding of child development but also assist the researchers and practitioners about providing appropriate strategies, tools, and materials suitable for children. Hence, it's not surprising that almost every teacher training program and educational programs for children include observational techniques to assess the child development and inform educational practice.

Observing is a valuable research and educational tool vastly used by the researchers and teachers. The best way to be acknowledged about young children's learning and development is observing play. Through observing play, the teachers and researchers can elicit information about each child's learning capacity and interests, motives underlying certain behaviors, and those observations can inform the best individualized educational practices and theories (Neaum, 2016). In the educational practice, observing brings individuality and better opportunities to know about the authentic traits of a child. Therefore, preschool teachers are suggested to use ongoing observations as a way of being proactive and prevent possible problems that would arise in the classrooms (PennState Extention, 2018). The observation of young children's behavior in classrooms reveals significant data as a part of early childhood assessment. Lam (2008) suggested that since young children are familiar with their classroom surroundings, 
Observing young children's play: a brief review

the most appropriate way of assessment for young children would be the observation of play and classroom activities rather than using the standardized tests.

Play has been cited as a phenomenon rather than a scientific concept in the literature because of its complexity as a human behavior. Play is a quite complex human behavior together with its unique developmental and learning aspects. Then, the question would be how such a complex concept should be observed in a scientifically sound way? Johnson, Christie and Yawkey (1999) explained that according to the scientific research perspectives, the observation of play would be more systematic and objective, and the researchers should know what and how to look for. These scientific perspectives in observing play favored the use of structured tests, scales, and interviews in controlled settings (Germeroth, Bodrova, Day-Hess, Barker, Sarama, Clements \& Layzer, 2019). However, Palaiologou (2017) discussed that play is an intrinsically motivated, creative and flexible human behavior which does not comply with the main principles of standardized assessment. Play is an adventurous behavior in nature and assessing play behavior in children would oppose to the ontological meaning of play. On the other hand, the early childhood education programs which are based on the academic goals in literacy and math rely in the structured environments and assessments rather than play based assessment. As a result of their participatory action research, Palaiologou (2017) concluded that a functional assessment of child's play was not possible because of rich interactions between play behavior and environmental context.

The play observations had been undertaken in diverse research areas about child development and education for decades. Some of the studies have been focused on free play observations in classrooms (Berkhout, Bakkers, Hoekman \& Goorhuis-Brouwer, 2013) and outdoors (Dowdell, Gray \& Malone, 2011), some of them focused on the play behaviors among children (Rubin, Maioni $\mathcal{E}$ Hornung, 1976), parent-child (MacDonald E
Parke, 1984) and teacher-child interactions in play (Trawick-Smith \& Dziurgot, 2011). Furthermore, the studies undertaken in the field of special education and clinical psychology have sampled special populations in line with their research purposes. For instance; the playground observations have been conducted to assess the relationship between play date frequency and playground behavior of children with high-functioning autism spectrum disorders (Frankel, Gorospe, Chang \& Sugar, 2011). Nash and Schaefer (2010) also pointed out the benefits of free play observations in psychotherapy with preschool children. They explained that the dramatic play tools, sandbox, miniatures would help in engaging the child in free play and reveals about his developmental and emotional state.

Since play behavior has been associated with almost every area of child development, the tools focusing on different aspects of child's play should also have a sound theoretical background anchored in child development. Some of these tools and their theoretical backgrounds are delineated in the following paragraphs.

\section{The observational settings}

Dating back to the Ancient Greeks, the observation and reasoning have been the main tools of understanding behavior as required by the positivistic scientific stance (Cohen, Manion \& Morrison, 2002). Observations allow the researchers to reach generalizations. Researchers can choose to actualize their observations in natural or structured settings in line with their research purposes. Mukherji and Albon (2015) explained that laboratories are structured settings wherein the conditions are similar for all children which improves the scientific quality of study, at the same time in these structured settings, it would be difficult to see the everyday, typical behavior of children since these settings are not a part of children's daily life. However, they would allow to study the behaviors that are rare and difficult to observe in daily life (Berk, 2012). 
On the other hand, the naturalistic observations take part in everyday settings wherein children are surrounded with familiar conditions. The naturalistic observation is more convenient for smaller samples and it's widely used to observe children's interactions at the preschool settings (Crandell, Haines Crandell E Vander Zanden, 2012). However, the naturalistic settings have the disadvantage of not providing the same conditions for all children surrounded by other "external variables" so that hypothesis testing would not be run through naturalistic observations (Crandell et al., 2012).

However, the naturalistic observations give the researcher the chance to observe the everyday behavior of children (Berk, 2012). Hence, naturalistic settings like home or classroom are favored especially for play observations since the play behaviors taking place in natural settings would be more authentic (Germeroth et al., 2019). Most of the observational studies of play take place in a nonparticipatory fashion wherein the researcher does not intervene in play so that authentic play behaviors of children would be observed. Johnson, Christie, and Wardle (2005) suggest that in order to observe a child's full range of play abilities there would be; (1) ample material to be involved in a variety of play types (e.g., balls, Legos, costumes), (2) enough time to be involved in more complex play behaviors, and (3) diverse settings like indoors and outdoors wherein children have the chance to involve in various behaviors.

\section{Types of observations}

Mukherji and Albon (2015) explained that if the researcher exactly knows what to look for and turns his data into numerical expression, then this type of research would be more quantitative in nature. Punch and Oancea (2014) also explained that the quantitative observations are highly structured and employ detailed observational agendas. On the contrary, if the researcher goes to the field with a common research purpose on his mind and pays attention to many things at once, this would be more qualitative in nature. There are three main techniques of data collection in qualitative studies; (1) naturalistic observation, (2) interviews, and (3) document analysis (Fraenkel \& Wallen, 2009). Qualitative data requires more time and effort devoted in the field. Generally qualitative observations are actualized in an unstructured and openended style, rather than evaluating behaviors on codes and classifications. Through open ended qualitative observations in the educational fields the researchers can generate hypothesis, and then through developing the structured observational tools, they can test those hypotheses in the quantitative studies (Punch \& Oancea, 2014). In the educational practice, quantitative assessments would be more favored in terms of assessing the effectiveness of the curriculum (Lam, 2008).

The type of observation also differs according to the degree of involvement of the researcher or teacher in the observational settings. Participant observation would require the involvement of the observer in preschool settings. Taking field notes while observing play requires the presence of the observer in the settings, on the other hand videotapes and classrooms equipped with one-way mirrors can provide the conditions for non-participatory observation.

\section{Tools to observe play}

There are many observational tools for play in the field from the less structured ones (e.g. anecdotes) to the highly structured ones (e.g. scales). In the following sections, some examples of scales, tools, anecdotes, and their use in the educational settings is briefly delineated.

\section{The Social/Cognitive Scale of Play Behavior}

This scale is considered as a checklist which is used to classify the play behavior of children on the cognitive (functional, construc- 
Observing young children's play: a brief review

tive, dramatic, games with rules) and social (solitary, parallel, group) levels. Checklists provide the observers with the definitions of what and how to look for. They would also be a part of the child's portfolio (Lam, 2008). This tool is consisted of four types of cognitive play and three types of social play, in total it provides 12 play categories and additional non-play behavior categories such as "unoccupied, onlooking, transition" and "activities". For instance, functional play is defined as the "repetitive muscle movements with or without objects", or parallel play is defined as "playing with toys or engaging in activities similar to those of other children who are in close proximity..., academic activities or teacher led activities are examples of nonplay behaviors (Johnson et al., 1999, p. 223).

Each of the cognitive play types can go with one of the three levels of social play. Rubin, Watson and Jambor (1978) developed these categories based on Piaget's cognitive levels and Parten's social levels of play. This tool can be used both by teachers and researchers and help in defining the children's overall play patterns. For instance, in their study of the observation of free play behaviors using this observational tool, Rubin et al. (1978) found that kindergartners aged 58-69 months displayed more group and dramatic play than preschoolers. In another study Christie, Johnsen and Peckover (1988) observed the indoor free play time of preschoolers and concluded that longer times of observation revealed more play behavior whereas shorter times of observations yielded more unoccupied/onlooking behavior. They suggested the extensions in free play time in preschools. In their study of social-cognitive play patterns in the same-age and mixed-age classrooms, Mounts and Roopnarine (1987) concluded that some developmental differences have been detected in the same age classrooms but not in the mixed age classrooms. Although checklists are used to gather objective and scientific data in observing child's play, they are limited in their scope and only the target play behaviors would be the focus of observation.

\section{Penn Interactive Play Scale}

The Penn Interactive Play Scale (PIPS) is administered by preschool teachers to measure the interactive play behaviors of preschool children (Fantuzzo, Sutton-Smith, Coolahan, Manz, Canning, Debnam, 1995). Play is considered as the most important tool for children to learn the social rules and values; hence preschools are generally the first place for children to learn how to get along with others. Developing the social competencies through play is significant for the young children coming from disadvantaged backgrounds. Through PIPS, the play relationships in the preschool classroom and play strengths of young children can be observed, and the findings can inform any possible intervention aiming to promote the adaptive play skills of children.

The scale was validated on young low-income children in the Head Start programs and revealed three dimensions as (1) play interaction (e.g. sharing ideas), (2) play disruption (e.g. starting fights and arguments), (3) and play disconnection (e.g. withdrawing). In their validity study, Fantuzzo, Coolahan, Mendez, McDermott and Sutton-Smith (1998) showed that children with high interactive play skills had higher social skills, whereas children with disruptive play patterns had involved more in solitary play. Fantuzzo, Mendez and Tighe (1998) also validated the parent version of PIPPS and suggested further use of it in play observations at home and school. The Spanish, Korean, and Chinese versions of PIPPS were also validated with the low-income Hispanic preschoolers, Korean preschool children, and low-income kindergarten children in Hong Kong (Castro, Mendez \& Fantuzzo, 2002; Choi \& Shin, 2008; Leung, 2014). Further Gagnon and Nagle (2004) measured peer interactive play and social competence and revealed significant relationships for at-risk preschool children. Besides, the PIPPS revealed significant relationships between peer interactions and peer interactive play for children and adolescents with autism. Children with more severe signs of autism were to develop less 
connections with peers at school. They concluded that the PIPPS would be a reliable tool in assessing the peer relationships of children and adolescents with autism.

\section{Make-Believe Play Observation Tool}

In respect to the importance of make-believe play for child's self-regulation and cognitive abilities from a Vygotskian perspective, Germeroth et al. (2019) developed the Mature Play Observation Tool (MPOT). Mature makebelieve play is defined as a play type in which children can step out from their pretend play scenario and talk about their ongoing play. The role representations are richer in mature make-believe play. The props little resemble the real objects symbolized in mature play.

Through MPOT, it's aimed to measure the quality of mature make-believe play in typical preschool classrooms. Preschool classrooms are one of the most authentic settings wherein the mature make-believe play of children would be observed in a rich social context. The MPOT also measures the teacher intervention in play which is considered as crucial in the zone of proximal development and possible outcomes for the children. Then, the teachers would develop better ways of scaffolding play depending on the observational results. The MPOT aims to be used in diverse settings and measure diverse abilities in social competence such as interpersonal interaction and self-expression. Because of its reliance on the sociocultural theory of Vygotsky and its emphasis on the richer social contexts, it seems that the MPOT is a promising play observation tool in line with the suggestions of Palaiologou (2017) on observing play behavior in a richer social context. Germeroth et al. (2019) also found out that children with better results on MPOT had performed better in literacy and numeracy.

\section{Visual data}

Videotape recordings provide detailed information about materials, interactions, language, and nonverbal gestures in play episodes. Since the videotaping materials are cheaper and accessible and the videos are easier to modify and store, more researchers choose using the videotapes for their research. In order to use the visual and audial recordings in naturalistic observation, additional care should be given not to disturb the events under investigation. Before collecting any kind of video, photo or sound recording from a classroom, it's important to have consent from the teachers and families. Teachers can also benefit from videotape recordings for their own use in class practice (Johnson et al., 2005). They can evaluate their own practice and make necessary changes in their practice and educational environment. Teachers can also share these videotape recordings with their fellows to discuss and enrich their teaching strategies. Videotapes would also be supporting for preschool teachers to evaluate their own in class performance (Wright, Ellis E Baxter, 2012).

\section{Anecdotes}

Anecdotes are the notes of significant acts in children's play and reveal detailed information about their developmental levels. If the observer can't make notes at the observation site, she can take notes depending on her recalls from the observation site and that's called vignettes (Johnson et al., 1999). Since vignettes are written after the observations, they could be more detailed than the onsite notes. The preschool teachers would prefer to write down vignettes rather than the anecdotes because of their convenience of writing after observation in a more comprehensive and detailed manner (Johnson et al., 2005).

Anecdotes are cited among the observational narrative techniques which give detailed developmental insights about a child and they show the possible paths of promoting development. These field notes can help in informing the educational programs and enriching the play environments (McFarland, 2008). While taking notes in the preschool classrooms, it's important for the observers to go to the class- 
Observing young children's play: a brief review

rooms with preliminary measures; such as (1) having clear goals about observation, (2) bringing note taking tools into the classroom, (3) noting down brief information about the time, place, and the identifiers for children, (4) transcribing the notes immediately after the observation, and (5) being objective.

Anecdotes as a part of the narrative accounts used by the preschool teachers would be a part of the portfolio. Through collecting the narrative accounts in the child's portfolio, the teachers can follow the child's learning and developmental path. It's also important for teachers to share those narratives with parents so that the parents would also be acknowledged about the child's development (Lam, 2008).

The table below summarizes the advantages and disadvantages of the observational techniques.

\begin{tabular}{|c|c|c|}
\hline & Advantages & Disadvantages \\
\hline $\begin{array}{l}\text { Scales and } \\
\text { structured tools }\end{array}$ & $\begin{array}{l}\text { - Application is clear through the } \\
\text { manuals or instructions } \\
\text { - } \quad \text { Objective } \\
\text { - Time saving } \\
\text { - Testing hypothesis is possible } \\
\quad \text { intervention is possible }\end{array}$ & $\begin{array}{l}\text { Only the target behaviors could be } \\
\text { observed }\end{array}$ \\
\hline Anectodes & $\begin{array}{l}\text { - } \quad \text { Provides detailed information } \\
\text { - } \quad \text { Sharable with parents and } \\
\text { - } \quad \text { Informs further research and } \\
\text { educational practice } \\
\text { - Helps in generating hypothesis }\end{array}$ & $\begin{array}{l}\text { - Holds potential observer bias } \\
\text { The observer's presence could ruin } \\
\text { the natural process }\end{array}$ \\
\hline Visual data & $\begin{array}{l}\text { - } \text { Produces storable data for any further } \\
\text { - } \quad \text { Sharable with parents and } \\
\text { - } \quad \text { families } \\
\text { - Usable for any further research } \\
\text { - } \quad \text { Helps in generating hypothesis }\end{array}$ & $\begin{array}{l}\text { - Requires more extensive research and } \\
\text { consent process }\end{array}$ \\
\hline
\end{tabular}

Table 1: Advantages and disadvantages of play observation techniques

\section{The ethical considerations}

Implementing the observational methods with children require some essential considerations of ethical issues. All kind of research including humans as participants is required to protect their rights. Some of the important steps to consider while conducting observational studies in the preschool classrooms would be; (1) getting written consent from the parents and keeping them informed throughout the study, and (2) explaining the process to the children in accordance with their age and cognitive level and getting their consent (American Psychological Association, 2004). Palaiologou (2016) also suggests some further steps for informing parents about child observations; (1) informing the parents about observational process, (2) hav- ing their opinions and suggestions about the observations, (3) informing them about the availability of observational records in case of demand, and (4) keeping them involved and informed about the observations.

Another ethical consideration in observational research would be observer's bias. Every researcher and observer are influenced by their past experiences and perceive the world and others from his personal stance. Hence, the observers should try to be as objective as possible and control their bias and emotional attributions during the research process (Fraenkel \& Wallen, 2009). Considering the possible bias of one observer, it's suggested to employ two or more observers and cross check the differences among the observations to achieve a higher level of reliability (Cohen, 
Manion E Morrison, 2002). One of the limitations of observing child's play would be the decontextualization of observed behaviors from the whole social context (Palaiologou, 2017). The play behaviors in preschools just like all human behaviors are shaped under certain social and cultural influences and observing some certain behaviors and coding those may shadow the larger socio-cultural context. It's inevitable that the observational data would always have relevance with the immediate and larger settings. Therefore, it would be useful to implement other complementary data collection methods such as interviews to inform the research and educational practice (Palaiologou, 2016).

\section{Conclusion}

Observing child's play has numerous benefits in the developmental and educational areas. Through observations in preschools, teachers and researchers can reach authentic and detailed information to inform their emerging curriculums and research. The end products of those observations such as photos, videotapes, anecdotes, vignettes, and scales can all be shared with other parties and families in need of joint decision-making regarding the child. The observational data can be kept in child's portfolio. Play-based portfolios would also include the interviews with children about their play episodes and preferences which in turn reflect their development and growth over time (Johnson et al., 2005).

\section{References}

American Psychological Association (2004): Report on ethical research with children released. Retrieved November 28, 2019.

URL: https://www.apa.org/monitor/julaug04/ report

Berk, L. E. (2012): Infants and children: prenatal through middle childhood (7th. Ed.). Allyn \& Bacon, Boston.

Berkhout, L., Bakkers, H., Hoekman, J. \& Goorhuis-Brouwer, S. M. (2013): Observing free play in classrooms with an instrument based on video analysis. Early Child Development and Care, 183/1, 125-136.

https://doi.org/10.1080/03004430.2012.658385

Castro, M., Mendez, J. L. \& Fantuzzo, J. (2002): A validation study of the Penn Interactive Peer Play Scale with urban Hispanic and African American preschool children. School Psychology Quarterly, 17/2, 109-127. https://doi.org/10.1521/scpq.17.2.109.20856

Choi, H. Y. \& Shin, H. Y. (2008): Validation of the Penn interactive peer play scale for Korean children. Korean Journal of Child Studies, 29/3, 303-318.

Christie, J. F., Johnsen, E. P. \& Peckover, R. B. (1988): The effects of play period duration on children's play patterns. Journal of Research in Childhood Education, 3/2, 123-131, https://doi.org/10.1080/02568548809594934.

Cohen, L., Manion, L. \& Morrison, K. (2002): Research methods in education (6th. Ed.). Routledge, London.

Crandell, T. L., Haines Crandell, C. \& Vander Zanden, J. W. (2012): Human development (10th. Ed.). McGraw Hill, New York.

Creswell, J. W. (2013): Qualitative inquiry \& research design (3rd. Ed.). Sage, Los Angeles.

Dowdell, K., Gray, T. \& Malone, K. (2011): Nature and its influence on children's outdoor play. Journal of Outdoor and Environmental Education, 15/2, 24-35. https://doi.org/10.1007/BF03400925

Fantuzzo, J., Sutton-Smith, B., Coolahan, K. C., Manz, P. H., Canning, S. \& Debnam, D. (1995): Assessment of preschool play interaction behaviors in young low-income children: Penn Interactive Peer Play Scale. Early Childhood Research Quarterly, 10/1, 105-120. https://doi.org/10.1016/0885-2006(95)90028-4.

Fantuzzo, J., Coolahan, K., Mendez, J., McDermott, P. \& Sutton-Smith, B. (1998): Contextually-relevant validation of peer play constructs with African American Head Start children: Penn interactive peer play scale. Early Childhood Research Quarterly, 13/3, 411-431. https://doi.org/10.1016/S0885-2006(99)80048-9

Fantuzzo, J., Mendez, J. \& Tighe, E. (1998): Parental assessment of peer play: Development and validation of the parent version of the Penn Interactive Peer Play Scale. Early Childhood Research Quarterly, 13/4, 659-676.

Frankel, F. D., Gorospe, C. M., Chang, Y. C. \& Sugar, C. A. (2011): Mothers' reports of play dates and observation of school playground 
Observing young children's play: a brief review

behavior of children having high functioning autism spectrum disorders. Journal of Child Psychology and Psychiatry, 52/5, 571-579. https://doi.org/10.1111/j.1469-7610.2010.02318.x

Fraenkel, J. R. \& Wallen, N. E. (2009): How to design and evaluate research in education? (7th. Ed.). McGraw Hill, Boston.

Gagnon, S. G. \& Nagle, R. J. (2004): Relationships between peer interactive play and social competence in at risk preschool children. Psychology in the Schools, 41/2, 173-189.

Germeroth, C., Bodrova, E., Day-Hess, C., Barker, J., Sarama, J., Clements, D. H. \& Layzer, C. (2019): Play it high, play it low: Examining the reliability and validity of a new observation tool to measure children's make-believe play. American Journal of Play, 11/2, 183-221.

Johnson, J. E., Christie, J. F. \& Yawkey, T. D. (1999): Play and early childhood development. Longman, New York.

Johnson, J. E., Christie, J. F. \& Wardle, F. (2005): Play, development, and early education. Pearson, Boston.

Jones, R. M., Pickles, A. \& Lord, C. (2017): Evaluating the quality of peer interactions in children and adolescents with autism with the Penn Interactive Peer Play Scale (PIPPS). Molecular Autism, 8/28

https://doi.org/10.1186/s13229-017-0144-x

Lam, T. C. M. (2008): Early childhood education assessment. In: Grotewell, P. G., \& Burton, Y. R. (Eds.) Early childhood education: Issues and developments. Nova Science, New York, 233-247.

Leung, C. H. (2014): Validation of the Penn Interactive Peer Play Scale with preschool children in low-income families in Hong Kong. Early Child Development and Care, 184/1, 118-137. https://doi.org/10.1037/t33146-000

MacDonald, K. \& Parke, R. D. (1984): Bridging the gap: Parent-child play interaction and peer interactive competence. Child Development, $55 / 4,1265-1277$.

McFarland, L. (2008): Anecdotal records: Valuable tools for assessing young children's development. Dimensions of Early Childhood, 36/1, 31-36.

Mounts, N. S. \& Roopnarine, J. L. (1987): Socialcognitive play patterns in same-age and mixed-age preschool classrooms. American Educational Research Journal, 24/3, 463-476. https://doi.org/10.3102/00028312024003463

Mukherji, P. \& Albon, D. (2015): Research methods in early childhood: An introductory guide. (2nd. Ed.). Sage, Los Angeles.

Nash, J. B. \& Schaefer, C. E. (2010): Clinical and developmental issues in psychotherapy with preschool children: Laying the groundwork for play therapy. In: Schaefer, C. E. (Ed.) Play therapy for preschool children. American Psychological Association, Washington, 15-30.

Neaum, S. (2016): Child development for early years students and practitioners (3rd. Ed.). Learning Matters, London.

Palaiologou, I. (2016): Child observation: A guide for students of early childhood (3rd. Ed.). Sage, London.

Palaiologou, I. (2017). Assessing children's play: reality or illusion? The case of early years foundation stage in England, Early Child Development and Care, 187/8, 1259-1272, https://doi.org/10.1080/03004430.2017.1295233

PennState Extension (2018): Why observe children? Retrieved on November 30, 2019 URL: http://bkc-od-media.vmhost.psu.edu/ documents/HO_WhyObserveChildren.pdf

Punch, K. F. \& Oancea, A. (2014): Introduction to research methods in education (2nd. Ed.). Sage: Los Angeles.

Rubin, K. H., Maioni, T. L. \& Hornung, M. (1976): Free play behaviors in middle-and lower-class preschoolers: Parten and Piaget revisited. Child Development, 47/2, 414-419.

Rubin, K. H., Watson, K. S. \& Jambor, T. W. (1978): Free-play behavior in preschool and kindergarten children. Child Development, 48, 534-536.

Trawick-Smith, J. \& Dziurgot, T. (2011): 'Goodfit' teacher-child play interactions and the subsequent autonomous play of preschool children. Early Childhood Research Quarterly, 26/1, 110-123.

Wright, M. R., Ellis, D. N. \& Baxter, A. (2012): The effect of immediate or delayed videobased teacher self-evaluation on Head Start teachers' use of praise. Journal of Research in Childhood Education, 26/2, 187-198.

Kurt, Gökce (2019): Observing young children's play: a brief review. Gyermeknevelés, 7. 2-3. sz., $20-27$. 